\title{
Smartphones as consumption tools: The adoption of Internet-enabled devices for shopping purposes
}

\author{
Cristian Florin Ciurlău ${ }^{1, *}$, Cătălin Kanty Popescu², and Geambazi Petris ${ }^{2}$ \\ 1"Dimitrie Cantemir" Christian University, Department of Economics, Splaiul Unirii 176, 040042, \\ Bucharest, Romania \\ ${ }^{2}$ The Bucharest University of Economic Studies, Department of Economics, Piața Romană 6, 010374, \\ Bucharest, Romania
}

\begin{abstract}
.
Research background: We develop a conceptual framework based on a systematic and comprehensive literature review on smartphones as consumption tools globally.

Purpose of the article: Building our argument by drawing on data collected from Comscore, Econsultancy, and Statista, we performed analyses and made estimates regarding the adoption of Internet-enabled devices for shopping purposes: selected retail and shopping activities of EU smartphone users, most popular mobile shopping apps in the U.S. (by reach), adults in the EU who never make purchases on mobile devices (by gender), and consumers who use a mobile device for product research while shopping in-store worldwide (by country).

Methods: The data for this research were gathered via an online survey questionnaire and were analyzed through structural equation modeling on a sample of 4,200 respondents.

Findings \& Value added: Smartphones have permeated the online community swiftly. The difficult task retailers confront is in obtaining consumers' mutual support in supplying the information required to provide a customized shopping experience. Mobile payment privacy is associated with apprehensions that users may have concerning what will become of the data supplied when they adopt mobile payment. A satisfactory array of facilitating circumstances brings about greater purpose to adopt mobile shopping applications, especially when diverse viable functions such as convenience and swift purchase are provided. Intention to raise subsequent benefits from mobile buying should harmonize the lasting value predisposition of the mobile purchasers. The essential issue encountered by the service suppliers is how to turn the developing mobile payment operation into financial earnings.
\end{abstract}

Keywords: smartphone; Internet; shopping; mobile; payment

JEL Classification: $E 24 ; J 21 ; J 54 ; J 64$

\footnotetext{
* Corresponding author: cristianciurlau@yahoo.com
} 


\section{Introduction}

Smartphones have permeated the online community swiftly and mobile shopping offers auspicious market prospects for retailers. Mobile shopping necessitates smartphones and such buying behavior [1] cannot be unswervingly derived from computer-based online purchase one. Online proficiency and mobile experience both favorably involve the ownership of shopping applications. Browsing habits for non-shopping applications assists in grasping such possession. In comparison with online sales channels where inspecting any site shapes virtual purchase, preloaded applications are unsuccessful in clarifying mobile buying. Mobile purchases via shopping applications are elucidated by the browsing habits for such applications, being influenced exclusively by digital experience. The browsing configurations of the shopping applications in addition to all other determinants are of almost no predictive value. As practical knowledge in employing smartphones increases [2], consumers are doubtlessly to be exposed to a superior amount of applications [3].

\section{Conceptual Framework and Literature Review}

Mobile experience will decrease the perceived risks of downloading applications, making possible the ownership of a greater quantity of shopping applications. Previous experience curtails the expenses related to conducting comparable activities moving along [3]. Personal creativity and perceived risk are instrumental in planning to adopt mobile shopping applications. Consumers who are extremely advanced and having a superior purpose to adopt mobile shopping applications are to a smaller extent sensitive to price [4].

Mobile payment privacy is associated with apprehensions that users may have concerning what will become of the data supplied when they adopt mobile payment. Regarding technologies that entail private information exchange [5], mobile payment may bring about apprehensions [6] about decline of control with respect to data and confidentiality. As mobile payment encompasses banking statistics, users may be concerned relative to imaginable financial losses. Mobile payment self-efficacy considerably shapes perceived effortlessness [7] in utilization and perceived practicality of mobile payment [8], determining mobile payment attitude, which influences intention to adopt mobile payment. Privacy issues alters attitude in relation to mobile payment and mobile payment adoption purpose. New technology anxiety affects perceived effortlessness in utilization of mobile payment [9], but not perceived practicality of mobile payment [10].

The difficult task retailers confront is in obtaining consumers' mutual support in supplying the information required to provide a customized shopping experience. Numerous users are hesitant to furnish retailers details about their geographical position, collect superfluous push messages, or offer personal data. A mobile application helps retailers to provide the customer-oriented commitment [11] that mobile-powered users demand. Retailers often require both mobile websites and applications to satisfy the requests of such consumers. Taking into account the mobile-powered users' predispositions for flexible website involvement [12], efficient retailers concentrate their adjustable tactic on enhancing their websites to comply with the requirements of their consumers more adequately. Retailers should move forward and equip their stores with digital technologies that link them to all components of the retail environment [13].

\section{Methodology and Empirical Analysis}

We develop a conceptual framework based on a systematic and comprehensive literature review on smartphones as consumption tools globally. Building our argument by drawing 
on data collected from Comscore, Econsultancy, and Statista, we performed analyses and made estimates regarding the adoption of Internet-enabled devices for shopping purposes: selected retail and shopping activities of EU smartphone users, most popular mobile shopping apps in the U.S. (by reach), adults in the EU who never make purchases on mobile devices (by gender), and consumers who use a mobile device for product research while shopping in-store worldwide (by country). The data for this research were gathered via an online survey questionnaire and were analyzed through structural equation modeling on a sample of 4,200 respondents. Survey method: The interviews were conducted online and data were weighted by five variables (age, race/ethnicity, gender, education, and geographic region) so that each country's sample composition reliably and accurately reflects the demographic profile of the adult population according to the country's most recent census data. Sampling errors and test of statistical significance take into account the effect of weighting. Stratified sampling methods were used and weights were trimmed not to exceed 3. Average margins of error, at the $95 \%$ confidence level, are $+/-2 \%$. For tabulation purposes, percentage points are rounded to the nearest whole number. The precision of the online polls was measured using a Bayesian credibility interval. An Internet-based survey software program was utilized for the delivery and collection of responses.

\section{Results and Discussion}

Intention to raise subsequent benefits from mobile buying should harmonize the lasting value predisposition of the mobile purchasers. The social attribute of mobile shopping meets the requirements of consumers who extol the virtues of social interactions [14], being less satisfactory to users clinging to individualism. Consumers who attach importance to low power distance are likely to place emphasis more on security and privacy of their identities and rights. Benefits of mobile shopping are particularly appealing to consumers who hold in high regard incremental advantages, expense saving, and ensuing incentive. Mobile purchasers having continuing orientation are standard loyal customers. Mobile vendors should adopt the most leading-edge technology and policies [15] to catalyze an authentically data-safe and privacy secured mobile purchase routine on the smartphone platform, to enhance customers' perceptions, and to underpin user continuance purposes [16]. (Table 1)

Table 1. Selected retail and shopping activities of EU smartphone users (\%)

\begin{tabular}{|l|r|}
\hline Used phone in retail store & 51 \\
\hline Found store location & 28 \\
\hline Purchased goods/services & 27 \\
\hline Compared product prices & 24 \\
\hline Researched product features & 23 \\
\hline Made shopping lists & 28 \\
\hline Checked product availability & 23 \\
\hline Found coupons/deals & 22 \\
\hline Used deal-a-day/group shopping & 18 \\
\hline Used mobile payments POS & 9 \\
\hline
\end{tabular}

Sources: Comscore; Econsultancy; our survey among 4,200 individuals conducted April 2020. 
A satisfactory array of facilitating circumstances brings about greater purpose to adopt mobile shopping applications, especially when diverse viable functions such as convenience and swift purchase are provided. Both privacy risk and security risk may be a major hindrance [17] to the acceptance of mobile shopping applications. Retailers should supply more efficient security in transaction and privacy protection to cut down the obstacles generated by perceived risk, giving rise to a boost in the adoption of mobile shopping applications [18]. (Table 2)

Table 2. Most popular mobile shopping apps in the U.S. (\%, by reach)

\begin{tabular}{|l|r|l|r|l|r|}
\hline Amazon (main) & 80.5 & Best Buy (main) & 13.7 & Coupons.com & 8.8 \\
\hline Walmart (main) & 44.3 & Kohl's & 12.8 & Ebates Cash Back \& Coupons & 8.4 \\
\hline eBay (main) & 35.8 & Walgreens (main) & 12.4 & Kroger & 8.5 \\
\hline Target (main) & 25.7 & Craigslist & 11.9 & Ticketmaster & 7.8 \\
\hline Ibotta & 23.6 & shopkick & 11.8 & Fetch Rewards App & 7.7 \\
\hline Groupon (main) & 20.5 & Macy's (main) & 11.7 & Chewy & 7.6 \\
\hline The Home Depot & 17.3 & Wayfair & 9.5 & Checkout 51 & 7.4 \\
\hline Etsy & 16.9 & Domino's & 9.4 & letgo & 7.4 \\
\hline Lowe's & 14.6 & Sam's Club (main) & 8.6 & DoorDash & 7.3 \\
\hline Wish (main) & 13.7 & RetailMeNot & 8.5 & Costco & 7.2 \\
\hline
\end{tabular}

Sources: Statista; our survey among 4,200 individuals conducted April 2020.

Online marketers and application developers need to supply more innovative and adequate components on their shopping applications, making buying experience more userfriendly, expeditious and practical for consumers. Shopping application developers should conceive the user interface to be time-saving and effortless in navigation: thus shopping applications are delectable for customers with interactive characteristics [19] to engage them and improve the entire shopping experience. Sophisticated degrees of participation and satisfaction make possible higher purpose to adopt applications [18]. (Table 3)

Table 3. Adults in the EU who never make purchases on mobile devices (\%, by gender)

\begin{tabular}{|l|r|}
\hline Male & 14 \\
\hline Female & 13 \\
\hline
\end{tabular}

Sources: Statista; our survey among 4,200 individuals conducted April 2020.

The essential issue encountered by the service suppliers is how to turn the developing mobile payment operation into financial earnings. Users' degrees of positive attitude and creativity are irrelevant determinants, whereas apprehension emerged is a negligible inhibitor of their willingness to use mobile payment services. Users' perceived convenience and conformity [20] represent important determinants, whereas lack of confidence, perceived expense, and perceived risk considerably hinder the use of mobile payment services. The value of mobile payment transactions needs to be unambiguous and devoid of any undisclosed expenditures that may hamper the use of the payment application. To expand acceptance, mobile payment service suppliers should consider optimizing the benefits to consumers [21] while maintaining the transaction expenses to a minimum. Individuals' purpose to use mobile payment services is shaped by the amount of involved retailers, which then has an impact on the prospects available to users to adopt such operations [22]. (Table 4) 
Table 4. Consumers who use a mobile device for product research while shopping in-store worldwide (\%, by country)

\begin{tabular}{|l|c|}
\hline United Kingdom & 71.8 \\
\hline United States & 75.4 \\
\hline Australia & 79.3 \\
\hline Canada & 79.9 \\
\hline Indonesia & 84.6 \\
\hline Russia & 85.8 \\
\hline Philippines & 86.3 \\
\hline South Africa & 86.6 \\
\hline Mexico & 88.6 \\
\hline Colombia & 91.2 \\
\hline Turkey & 95.2 \\
\hline
\end{tabular}

Sources: Statista; our survey among 4,200 individuals conducted April 2020.

\section{Conclusions and Implications}

Consumer adoption of mobile payment is inferior by contrast with the acceptance of established types of payments. Absence of user trust is the most important lasting obstacle [23] for the ascendancy of mobile finances systems. Perceived quality of information, of system, and of service as the primary trust catalysts [24] is favorably associated with primary trust constitution, while perceived indecision as the primary trust obstacle generates a relevant adverse impact on primary trust in mobile payment acceptance. Primary trust favorably influences perceived benefit and perceived convenience - all these three components in unison conjecturing usage purposes. Perceived practicality of mobile payment has a favorable impact on perceived advantage [25].

\section{References}

1. Mihăilă, R. (2018). The ascendance of postmodernism in the educational sphere. Educational Philosophy and Theory, 50(14), 1578-1579.

2. Lăzăroiu, G. (2018). Postmodernism as an epistemological phenomenon. Educational Philosophy and Theory, 50(14), 1389-1390.

3. Kim, M., Kim, J., Choi, J., Trivedi, M. (2017). Mobile shopping through applications: Understanding application possession and mobile purchase. Journal of Interactive Marketing, 39, 55-68.

4. Natarajan, T., Balasubramanian, S. A., Kasilingam, D. L. (2017). Understanding the intention to use mobile shopping applications and its influence on price sensitivity. Journal of Retailing and Consumer Services, 37, 8-22.

5. Ionescu, D. (2020). Deep learning algorithms and big health care data in clinical natural language processing. Linguistic and Philosophical Investigations, 19, 86-92.

6. Ashander, L., Kliestikova, J., Durana, P., Vrbka, J. (2019). The decision-making logic of big data algorithmic analytics. Contemporary Readings in Law and Social Justice, 11(1), 57-62.

7. Fincham, S. (2019). Internet of Things-based medical applications, wearable sensor systems, and real-time health monitoring. American Journal of Medical Research, 6(2), 49-54. 
8. Lăzăroiu, G., Kovacova, M., Siekelova, A., Vrbka, J. (2020). Addictive behavior of problematic smartphone users: The relationship between depression, anxiety, and stress. Review of Contemporary Philosophy, 19, 50-56.

9. Hollowell, J. C., Kollar, B., Vrbka, J., Kovalova, E. (2019). Cognitive decision-making algorithms for sustainable manufacturing processes in Industry 4.0: Networked, smart, and responsive devices. Economics, Management, and Financial Markets, 14(4), 9-15.

10. Bailey, A. A., Pentina, I., Mishra, A. S., Mimoun, M. S. B. (2017). Mobile payments adoption by US consumers: An extended TAM. International Journal of Retail \& Distribution Management, 45(6), 626-640.

11. Bratu, S. (2019). Psychological and contextual risk factors related to problematic smartphone use: Depression and anxiety symptom severity. Analysis and Metaphysics, $18,64-70$.

12. Popescu Ljungholm, D. (2019). The safety and reliability of networked autonomous vehicles: Ethical dilemmas, liability litigation concerns, and regulatory issues. Contemporary Readings in Law and Social Justice, 11(2), 9-14.

13. Faulds, D. J., Mangold, W. G., Raju, P. S., Valsalan, S. (2018). The mobile shopping revolution: Redefining the consumer decision process. Business Horizons, 61(2), 323338.

14. Berke, S. (2019). The sustainable development of data-driven smart cities: Citizencentered urban governance and networked digital technologies. Geopolitics, History, and International Relations, 11(1), 122-127.

15. Fielden, A., Michalkova, L., Vrbka, J., Lyakina, M. (2019). Smart sustainable datadriven manufacturing: Cyber-physical production systems and Internet of Things sensing networks. Journal of Self-Governance and Management Economics, 7(4), 7-13.

16. Lu, J., Yu, C.-s., Liu, C., Wei, J. (2017). Comparison of mobile shopping continuance intention between China and USA from an espoused cultural perspective. Computers in Human Behavior, 75, 130-146.

17. Gradeck, J., Neguriţă, O., Grecu, I., Grecu, G. (2019). Big data analytics in Industry 4.0: Sustainable industrial value creation, manufacturing process innovation, and networked production structures. Journal of Self-Governance and Management Economics, 7(3), 34-40.

18. Chopdar, P. K., Korfiatis, N., Sivakumar, V. J., Lytras, M. D. (2018). Mobile shopping apps adoption and perceived risks: A cross-country perspective utilizing the Unified Theory of Acceptance and Use of Technology. Computers in Human Behavior, 86, 109-128.

19. Heuston, D. (2019). Medical big data processing mechanisms and real-time patient health monitoring. American Journal of Medical Research, 6(2), 55-60.

20. Pera, A. (2019). Towards effective workforce management: Hiring algorithms, big data-driven accountability systems, and organizational performance. Psychosociological Issues in Human Resource Management, 7(2), 19-24.

21. Nica, E., Miklencicova, R., Kicova, E. (2019). Artificial intelligence-supported workplace decisions: Big data algorithmic analytics, sensory and tracking technologies, and metabolism monitors. Psychosociological Issues in Human Resource Management, $7(2), 31-36$.

22. Humbani, M., Wiese, M. (2018). A cashless society for all: Determining consumers' readiness to adopt mobile payment services. Journal of African Business, 19(3), 409429. 
23. Atwell, G. J., Kicova, E., Vagner, L., Miklencicova, R. (2019). Parental engagement with social media platforms: digital mothering, children's online privacy, and the sense of disempowerment in the technology-integrated society. Journal of Research in Gender Studies, 9(2), 44-49.

24. Eskridge, M. (2019). Falling in love with algorithmic compatibility in a digital dating landscape: Sexually affective data, networked intimacy, and online gendered identity constructions. Journal of Research in Gender Studies, 9(2), 92-98.

25. Gao, L., Waechter, K. A. (2017). Examining the role of initial trust in user adoption of mobile payment services: an empirical investigation. Information Systems Frontiers, 19(3), 525-548. 